\title{
Evidence Based Skin Care in Preterm Neonates- A Short Review
}

\author{
Sumandeep Kaur ${ }^{1}$, Navdeep S Sidhu ${ }^{2}$ \\ ${ }^{1} \mathrm{PhD}$ Scholar, Desh Bhagat University, Mandi Gobindgarh, Tutor, University College of Nursing, Faridkot, \\ Punjab, India \\ ${ }^{2}$ Assistant Professor, Guru Gobind Singh Medical College, Faridkot, Punjab, India
}

Corresponding Author: Navdeep S Sidhu

\begin{abstract}
Preterm neonates are the neonates born alive before completion of 37 weeks of gestation. Prematurity is the real threat for survival of these neonates, especially those who are verypreterm (less than 32 weeks). In developing countries due to lack of basic care such as maintenance of warm chain, breast feeding support, infection control and scarcity of resources to tackle respiratory difficulties; the mortality in preterm infants is very high. Good skin care is a critical component of the basic neonatal care, that can directly reduce complications of prematurity as well address issues arising during the handling of these preterm infants such as injuries due to adhesives or devices, skin dryness, the use of skin emollients and disinfectants etc. In contemporary era, evidence-based practices are the need of hour to guide clinical practice. There are limited research articles dealing with skin care in preterm neonates that offer strong recommendations for skin care modalities. In this short review, the authors have compiled the recent evidences to address various issues related to skin care in very preterm neonates. In this article the evidences related to bathing practices in preterm infants, and the use of disinfectants and emollients for premature skin care has been discussed; besides making general recommendation related to skin care in preterm infants.
\end{abstract}

Key Words: Preterm, skin care, emollients, disinfectant, neonate, prematurity, premature skin

\section{INTRODUCTION}

Global incidence of preterm births is around $18 \%$ and out of these $23 \%$ preterm births occur in India. Prematurity is the leading cause of death in under 5 children. Also rate of prematurity is increasing in almost all countries. ${ }^{[1,2]}$ These preterm neonates need extra attention in different areas of care to prevent mortality and morbidity. Skin care is one of the challenging aspects of the preterm care.

Skin is the largest human organ that acts as the first line of defense against external irritants and pathogens, besides maintaining normal temperature and hydration. It consists of three layers: epidermis, dermis and hypodermis. Stratum corneum is the outermost part of epidermal layer and is the most critical component in subserving the barrier and thermoregulatory functions of the skin. In early preterm neonates ( $<34$ weeks of gestation), the skin development and its functioning are suboptimal which put these newborn infants at massive disadvantage in terms of barrier and sensory function and in the regulation of temperature and hydration. ${ }^{[3]}$

\section{Skin development in relation to gestation age:}

In fetal life, stratum corneum formation starts at 21 weeks of gestation and is completed by 32 weeks of gestation. Sebum glands development occurs at 16-18 weeks. Vernix caseosa is developed till third trimester which makes fetus waterproof and 
shields it against constant exposure of amniotic fluid. At around 26 weeks of gestation subcutaneous fat deposition occurs in the form of white and brown fat. Brown fat helps to maintain temperature by releasing heat from oxidation of fatty acids. In a normal term born infant, the stratum corneum is more than 15 layers in thickness, same as the adult skin. After birth, the extra -uterine life stimulates skin maturation and degree of maturation depends upon the gestational age of the newborn.

\section{Key differences in term and preterm skin:}

1. Stratum corneum: in term neonates it is well developed and has 15 to 20 layers. In preterm neonates it is less developed, containing only 2 to 3 layers. This leads to impairment in the barrier function of skin in the preterm neonates. ${ }^{[3-5]}$

2. There is difference in cohesiveness of the epidermis to the dermis between term and preterm neonates. In preterm neonates the fibrils responsible for cohesion between dermis and epidermis are less in number and are more widely spaced as compared to those in term neonates. Decreased cohesiveness of these layers in preterm neonates make the skin of these neonates more susceptible to injury. ${ }^{[3-5)}$

3. There is difference in skin surface $p H$ between term and preterm neonates. Most of term and preterm neonates have alkaline skin surface with $\mathrm{pH}>6$. In term neonates the skin $\mathrm{PH}$ usually decreases to $<5$ within first 3 days of life. This "acid barrier" provides protection against pathogens. The skin of preterm neonates has immature structure with decreased or negligible amount of vernix caseosa and takes longer time for its $\mathrm{pH}$ to decrease to acidic values. In preterm neonates the skin $\mathrm{pH}$ may take several weeks to decrease to value of $\mathrm{pH} 5$ and during this period preterm neonates are more susceptible to infections. ${ }^{[3-5]}$
4. In case of preterm neonates less stores of subcutaneous brown fat are found. This leads to an inadequate thermoregulatory function of the skin in the preterm neonates. ${ }^{[3-5]}$

These anatomical and physiological differences in the skin make preterm neonates more susceptible to physical and thermal injuries and to infections. In addition to this, neonatal intensive care unit (NICU) admission of these preterm neonates is associated with high risk of breakdown in skin integrity related to routine invasive procedure in NICU. To deliver quality in preterm skin care, a thorough assessment of the skin condition is of foremost importance. Skin assessment can be done using various tools such as neonatal skin condition score (NSCS), skin erythema scale, direct specific observation etc. Neonatal skin condition score is widely used and includes three sub-scales related to skin dryness, erythema and breakdown/ excoriation. ${ }^{[6]}$

Another important aspect of skin care is to identify potential areas of risk factors that affect protective functions of skin. Factors that can contribute to impaired skin integrity are arterial and venous puncture, use of topical emollients, removal of adhesives, altered skin integrity under phototherapy and radiant warmers due to transcutaneous water loss. ${ }^{[7]}$ All of these factors need to be adequately addressed by the health care team to ensure high quality skin care.

\section{Evidences related to best practices in skin care of premature neonates:}

Various evidences to address the issues in preterm skin care in NICU like delay in bathing, use of skin disinfectants, use of emollients are discussed here:

1. Evidence based practices in delay in bathing: Bathing may result in forceful removal of vernix caseosa, hypothermia and instability of vital signs. Guidelines by Association of Women's Health Obstetric and Neonatal Nurses 
(AWHONN) recommend that a newborn with stable body temperature and vital signs can take a bath after 2-4 hours of birth, [8] where World Health Organization (WHO) guidelines recommend that first bath should be delayed until 6 hours of birth. ${ }^{[9]}$ In case of preterm neonates, the timing of first bath depends on the stability of vital signs like temperature, heart rate, respiratory rate and often needs to be delayed for several hours until these parameters are stable. [8] Both AWHONN and WHO guidelines suggest that first bath should be gentle, without antiseptic and should not result in abrupt and complete removal of vernix. Another important recommendation by AWHONN is the alternating use of soap along with water in the bathing of preterm infants. Also, the use of neutral $\mathrm{pH}$ soaps should be encouraged. In case of preterm infants $<32$ weeks of gestation, AWHONN recommends the use of only warm water with cotton balls for bathing.

2. Evidences in use of skin disinfectants and emollients: a variety of skin disinfectants and emollients are available for skin care in newborns. Various disinfectants include isopropyl alcohol, povidone-iodine, chlorhexidine etc., whereas different emollients include as Aquaphor ointment, no-sting, coconut oil, sunflower seed oil, olive oil etc. These products have their own benefits and limitations and hence their use should be evidence based.

In preterm neonates, routine use of alcohol-based antiseptics should not be practiced due to risk of burns or severe dermatitis. [10-13] A safer topical antiseptic option can be use of 0.05-2\% w/v Chlorhexidine. ${ }^{[11]}$ Similarly, use of antiseptics like iodinated povidone is not recommended in preterm neonates, as skin barrier is week in these neonates and topical application can penetrate the skin and ultimately lead to systemic effects including thyroid dysfunction. ${ }^{[10-}$

Emollient use has been found to protect premature skin of neonates and decrease the chances of skin tearing or stripping. Use of Aquaphor and no-sting has been found to be effective in skin protection and result in reduction of transcutaneous water loss. ${ }^{[14]}$ Many older studies had raised concerns of increased rates of neonatal sepsis with the use of emollients, ${ }^{[15,16]}$ but a recent metaanalysis has suggested that topical emollients may have little or no impact on the rates of invasive infection and mortality. ${ }^{[17]}$

Studies related to traditional use of mustard oil and olive oil have shown their use can adversely alter the skin integrity, hence the use of these oils should be discouraged. Instead, the use of vegetable oils rich in linoleic acid such as sunflower oil and of coconut oil has been shown to improve the barrier function of the skin and to lower the rates of infection. Therefore, the used of coconut oil (especially virgin coconut oil) and sunflower oil (especially highlinoleate sunflower oil) should be encouraged for the care of premature skin. ${ }^{[18,19]}$

\section{General recommendations for skin care in premature neonates:}

Some of the simple evidence-based cost-effective interventions that healthcare personnel/nurses/caregiver can adapt while delivering the skin care to preterm infants are:

1. Meticulous hand washing should be done before touching the neonate and also after the procedures. WHO guidelines should be followed for maintaining hand hygiene and health education should be provided to parents and caregivers to maintain hand hygiene. ${ }^{[2}$

2. Thermoneutral environment should be maintained around the preterm infant 
and handling of these babies should be minimized.

3. Relative humidity of the air inside the incubator should be more than $70 \%$ during first seven days of life and it may be gradually decreased to $50 \%$ after the first week, until the child is 4 weeks old. [9]

4. Kangaroo mother care (KMC) should be practiced for all clinically stable preterm infants and low birth weight neonates as this has been shown to enhance the mother-child bond, provides better sensory stimulation of the infant, and reduces the pain and stress of preterm infants. ${ }^{[10]}$

5. Frequent change of position must be practiced especially when neonate is under phototherapy and radiant warmer or is inside the incubator. Swaddling and nesting of the newborn should be routinely done to simulate intra-uterine position. This position provides comfort to newborn, minimizes the heat loss and provides additional benefit of stimulation to promote growth and development. ${ }^{[10}$

6. Care must be taken while removing the adhesives. Gentle removal of adhesives should be practiced by applying coconut or sunflower oil before slow manipulation of adhesives.

7. A good method to prevent transcutaneous water loss and to minimize unnecessary touching and boost skin protection is by using polyethylene caps and wraps, which have been shown to be more effective in preventing the heat loss as compared to conventional drying methods.

8. WHO recommendations for dry cord care and special emphasis on keeping the diapers below the level of cord stump to avoid contamination should be followed. Nothing should be applied over stump, not even bandage to cover it. ${ }^{[20]}$

\section{CONCLUSION}

These simplified evidence-based recommendations in skin care of preterm neonates can help to improve quality of skin care especially by nursing personnel. Most of the interventions are cost effective and can be easily implemented in NICU. These recommendations can be refined further with addition of new evidences in the near future.

\section{Acknowledgement: None}

Conflict of Interest: None

\section{Source of Funding: None}

\section{REFERENCES}

1. Liu L, Oza S, Hogan D, et al. Global, regional, and national causes of under-5 mortality in 2000-15: an updated systematic analysis with implications for the Sustainable Development Goals. Lancet. 2016;388(10063):3027-35.

2. Blencowe H, Cousens S, Oestergaard M, et al. National, regional and worldwide estimates of preterm birth. The Lancet, June 2012. 9;379(9832):2162-72.

3. Moore KL, Persaud TVN. The integumentary system In: Moore KL, Persaud TVN, editors. The developing human, $7^{\text {th }}$ ed. Philadelphia: Saunders; 2003:485-502.

4. Carlon BM. Integumentary, skeletal and muscular systems In: Carlon BM, Editor. Human embryology and developmental biology. $3^{\text {rd }}$ ed. Missouri: Mosby: 2004; 173-207.

5. Taeusch HW, Ballard RA, Gleason CA. Newborn skin: Development and basic concepts In: MacDonald MG, Mullet MD, Seshia MMK, editors. Avery's Neonatalogy, Pathophysiology \& Management of the Newborn. $6^{\text {th }}$ ed. Philadelphia, Baltimore, New York, London, Buenos Aires, Hong Kong, Sidney, Tokyo: Lippincott Williams and Wilkins;2005:1471-82.

6. Lund $\mathrm{CH}$, Osborne JW. Validity and reliability of the neonatal skin condition score. J Obst Gyn Neo. 2004; 33:320-27.

7. Fontenele FC, Pagliuca LMF, Cardoso MVLML. Cuidados com a pele do recém- 
nascido: análise de conceito. Esc Anna Nery [Internet]. 2012;16(3):480-5. Available from: http://doi.org/10.1590/S141481452012000300008.

8. WHO recommendations on newborn health: guidelines approved by the WHO Guidelines Review Committee. World Health Organization; 2017 (WHO/MCA/17.07). Available from: https://apps.who.int , iris , bitstream , handle, WHO-MCA-17.07-eng.pdf. Accessed July 15, 2021

9. Association of Women's Health, Obstetric and Neonatal Nurses (AWHONN). (2018). Neonatal Skin Care: Evidence-Based Clinical Practice Guideline, 4th Edition: Washington, DC

10. Madhu R, Vijayabhaskar C, Anandan V, et al. Indian Academy of Pediatrics Guidelines for Pediatric Skin Care. Indian Pediatr. 2021 Feb 15;58(2):153-161.

11. Sharma A, Kulkarni S, Thukral A, et al. Aqueous chlorhexidine $1 \%$ versus $2 \%$ for neonatal skin antisepsis: a randomized noninferiority trial. Archives of Disease in Childhood - Fetal and Neonatal Edition Published Online First: 09 June 2021. doi: 10.1136/archdischild-2020321174

12. Peytavi UB, Lavender T, Jenerowicz D, et al. Recommendations from a European Round table Meeting on Best Practice Healthy Infant Skin Care. Pediatr Dermatol. 2016; 33: 311-21.

13. Aredes NDA, Santos RCA, Fonseca LMM. Skin care of premature newborns: integrative review. Rev Eletr Enferm [Internet]. 2017; 19:1-25. Available from: https://www.revistas.ufg.br/fen/article/view/ 43331/25159

14. Brandon DH, Coe K, Hudson-Barr D, et al. Effectiveness of No-Sting skin protectant and Aquaphor on water loss and skin integrity in premature infants. J Perinatol
[Internet]. $2010 \quad$ [cited 2017 dec31];30(6):414-9. Available from: http://doi.org/10.1038/jp.2009.174.

15. Edwards WH, Conner JM, Soll RF. The effect of prophylactic ointment therapy on nosocomial sepsis rates and skin integrity in infants with birth weights of 501 to $1000 \mathrm{~g}$. Pediatrics 2004; 113(5): 1195-1203.

16. Conner JM, Soll RF, Edwards WH. Topical ointment for preventing infection in preterm infants. Cochrane Database Syst Rev 2004; (1) CD001150.

17. Cleminson J, McGuire W. Topical emollient for preventing infection in preterm infants. Cochrane Database of Systematic Reviews 2021, (5) CD001150.

18. Darmstadt GL, Mao-Qiang M, Chi E, et al. Impact of topical oils on the skin barrier: possible implications for neonatal health in developing countries. Acta Pediatr. 2002;91: 546-54.

19. Danby SG, AlEnezi T, Sultan A, et al. Effect of olive and sunflower seed oil on the adult skin barrier: Implications for neonatal skin care. Pediatr Dermatol. 2013; 30:42 50.

20. WHO recommendations on newborn health: guidelines approved by the WHO Guidelines Review Committee. World Health Organization; 2017 (WHO/MCA/17.07). Available from: https://apps.who.int , iris > bitstream , handle, WHO-MCA-17.07-eng.pdf. Accessed July 15, 2021.

21. Trevisanuto D, Doglioni N, Cavallin F, et al. Heat loss prevention in very preterm infants in delivery rooms: a prospective, randomized, controlled trial of polyethylene caps. J Pediatr. 2010 Jun; 156(6): 914-7

How to cite this article: Kaur S, Sidhu NS. Evidence based skin care in preterm neonates - a short review. International Journal of Research and Review. 2021; 8(7): 381-385. DOI: https://doi.org/10.52403/ijrr.20210754 